\title{
CONSCIÊNCIA MORAL E BIBLIOTECONOMIA: UMA ANÁLISE DOS GRAUS EXISTENCIAIS NAS ATIVIDADES DOS BIBLIOTECÁRIOS
}

\author{
MORAL CONSCIOUSNESS AND LIBRARIANSHIP: AN ANALYSIS OF LIBRARIANS' \\ ACTIVITIES
}

Stheve Balbinotti ${ }^{I}$

Recebido em: 09-01-2019

Aceito em: 16-03-2019

\begin{abstract}
Resumo
O objetivo deste artigo é exemplificar, traçando uma breve reflexão acerca dos graus da Consciência Moral nas atividades cotidianas dos bibliotecários. A metodologia consiste em pesquisa bibliográfica e observações sobre os assuntos Consciência, Moral e Consciência Moral. Destaca o conceito e as qualificações da consciência humana. Aponta breves definições sobre a Moral. Conclui que a Ética e a Moral são assuntos pouco aproveitados durante a graduação dos bibliotecários e que os mesmos, além de construir a sua própria Consciência Moral digna, também são capazes de ajudar na formação da Consciência Moral dos usuários e para o desenvolvimento da sociedade.
\end{abstract}

Palavras-chave: Biblioteconomia. Consciência Moral. Deontologia. Ética.

\begin{abstract}
The purpose of this article is to exemplify, drawing a brief reflection on the degrees of Moral Consciousness in the daily activities of librarians. The methodology consists of bibliographical research and observations on the issues of Consciousness, Moral and Moral Consciousness. It highlights the concept and qualifications of human consciousness. It points out brief definitions about Morals. It concludes that Ethics and Morals are subjects that are not much used during the graduation of librarians and that they, besides building their own moral Moral Consciousness, are able to help in the formation of Moral Conscience of the users and for the development of society.
\end{abstract}

Key words: Librarianship. Moral Consciousness. Deontology. Ethic

\section{INTRODUÇÃO}

Antes de iniciar o tema, é preciso esclarecer que quando nos referimos aqui a bibliotecário(s), estamos mencionando toda a categoria, independente de sexo ou gênero. Os passos percorridos durante o trajeto deste trabalho foram sob o viés da metodologia de pesquisa bibliográfica, observações e reflexões sobre os assuntos Consciência, Moral e Consciência Moral.

A Ética sempre esteve presente na história da humanidade e é impossível não estar ligado direta ou indiretamente aos costumes, hábitos, normas, leis e códigos impostos pela sociedade. Não importa o local, não importa o século, sempre haverá algo ético nas relações humanas.

Quando uma pessoa nasce, ela já começa a fazer parte da Ética automaticamente através de mecanismos controladores da sociedade, tais como às leis, regras e regulamentos que nasceram a partir do direito e possuem forte ligação com questões da Ética. Segundo o Código Civil brasileiro, é necessário um nome e documentos que comprovem a existência da pessoa e, quando ela morre, é preciso outro documento que comprove a sua morte. Neste exato momento,

\footnotetext{
' Universidade Federal do Rio Grande do Sul - e-mail: stheve@gmail.com
} 
através das linhas deste artigo, estamos dentro da Ética, pois precisamos seguir normas para concluir o texto.

Ao longo da vida pessoal e profissional, elaboram-se ideias e ideais que contribuem para a formação da consciência de cada ser. Através das boas e más experiências de vida, surge a Consciência Moral e esta delimita os caminhos que o indivíduo julga certo ou errado para seguir a sua jornada. A consciência é muito poderosa, pois ela é capaz de libertar ou manter em cárcere privado uma vida.

A Deontologia é uma área da Ética que estuda as profissões e é sob o seu viés que partimos para uma análise e exemplificações dos graus da Consciência Moral nas atividades profissionais dos bibliotecários. A Consciência Moral profissional é construída através de virtudes que levam ao desenvolvimento de atos bons ou de atos ilícitos por parte do profissional e destacamos algumas destas ações por parte dos bibliotecários no decorrer do texto.

A seguir, o texto assumirá a seguinte divisão: Consciência: conceito e qualificações; Moral: breves definições; Consciência Moral e seus graus existenciais nas atividades bibliotecárias; Reflexões finais.

\section{CONSCIÊNCIA: CONCEITO E QUALIFICAÇÕES}

A presença da consciência na vida do ser humano é um dos fatores que o tornam mais evoluído em comparação a outros animais e ela só existe onde há relações, não importando se boas ou más. Desde o período dos homens das cavernas, que demonstravam seus sentimentos através de desenhos nas paredes, até hoje em que os humanos modernos "postam" suas situações sentimentais em redes sociais.

O ser humano é um poço natural sem fundo de interesses. Através da pirâmide das necessidades, elaborada por Maslow, é possível ver esses interesses. Há interesses básicos para manter a sobrevivência e no topo da pirâmide existem os interesses de realizações pessoais. Nota-se que em todas as fases da pirâmide existem os interesses. Para enfrentar essas necessidades, o ser humano pode contar com a consciência, pois ela é capaz de agir como um mecanismo de defesa e/ou ataque junto a essas necessidades e buscas contínuas por realizações pessoais e profissionais.

Se as ações estão no cerne da sobrevivência e seu poder vincula-se à disponibilidade de imagens orientadores, então um mecanismo capaz de maximizar a manipulação eficaz de imagens a serviço dos interesses de um organismo específico conferiria uma enorme vantagem aos organismos que o possuíssem, e esse mecanismo provavelmente teria prevalecido na evolução. A consciência é precisamente esse mecanismo. (DAMÁSIO, 2000, p. 43-44).

Podemos definir a consciência como um mecanismo intelectual e particular de cada ser humano utilizado para orientação e reflexão das tomadas de decisões em situações de cunho psicológico e sentimental durante a sua existência.

\subsection{QUALIFICAÇÕES DA CONSCIÊNCIA}

Almeida (2005) afirma que a qualificação consciencial é o ato ou efeito de qualificar as manifestações da consciência. Visando dar maior ênfase ao cotidiano profissional dos bibliotecários, destacamos quatro qualificações para uma rápida observação: profissional, convivencial, assistencial e afetiva. 


\subsubsection{Qualificação profissional}

Independente da área de atuação, qualquer profissional que visa o sucesso e a felicidade para sua carreira pode usar a consciência como ferramenta de apoio para o desenvolvimento e manutenção de tais procedimentos. "A qualificação profissional é o ato ou efeito de qualificar os desempenhos profissionais, atribuindo maior qualidade às escolhas, envolvimentos, projetos e manejo do dinheiro no universo trabalhista." (ALMEIDA, 2005, p. 76).

A utilização da qualificação profissional da consciência pelos bibliotecários pode tornar a vida profissional dos mesmos menos complicada, pois esta qualificação quando presente na consciência do indivíduo pode ser capaz de projetar uma antevisão para detectar problemas e projetar futuras soluções.

\subsubsection{Qualificação convivencial}

Não existe nenhuma profissão no mundo em que não haja o mínimo possível de convivência com outras pessoas. Os estudantes de Biblioteconomia e os bibliotecários recém formados não devem pensar que a profissão se resume a esconder-se do mundo atrás dos livros ou no meio das estantes. "A qualificação convivencial é o ato ou efeito de qualificar as atuações pessoais dentro do convívio interconsciencial, atribuindo maior qualidade ao senso de compreensão e cooperação grupal.” (ALMEIDA, 2005, p. 50).

Quanto mais qualificada a consciência em relação ao convívio social, maiores as chances de obtenção de sucesso, principalmente no tratamento aos usuários inseridos em uma unidade informacional. Além do convívio social face a face, também é necessário ao bibliotecário ter consciência que precisa saber conviver socialmente nas redes sociais da web.

\subsubsection{Qualificação assistencial}

Dar assistência é uma atividade inserida automaticamente no cotidiano profissional dos bibliotecários. Desde Alexandria, os primeiros bibliotecários, Zenótodo de Éfeso, Apolônio de Rodes, Erastóstenes de Cirene e Calímaco de Cirene foram os pioneiros a apresentar para a sociedade os serviços da Biblioteconomia.

A qualificação assistencial é o ato de qualificar ou atribuir maior qualidade às intercessões pensênicas da consciência a favor do outro, em detrimento das manifestações inferiores, vulgares ou medíocres do egoísmo e da assedialidade. (ALMEIDA, 2005, p. 120).

Em uma sociedade exausta pelo egoísmo, ser consciente e saber dar assistência ao próximo é um ato de nobreza e isto segue aquilo que a Biblioteconomia coloca como sendo um de seus principais objetivos, que é dar assistência aos usuários das unidades de informação.

\subsubsection{Qualificação afetiva}

A qualificação consciente do afeto vai ao encontro das citadas anteriormente. Ser afetivo é se permitir ao próximo da mesma maneira que gostaria que o outro se permitisse a você. $\mathrm{O}$ afeto aqui é visto também como um ato de respeito ao próximo e é preciso uma dose de coragem para demonstrá-lo. "A qualificação afetiva é o ato de qualificar ou atribuir maior qualidade às emoções e sentimentos de afeição da consciência em detrimento das manifestações inferiores, vulgares ou medíocres da antifraternidade." (ALMEIDA, 2005, p. 86).

\subsection{AUTOCONSCIÊNCIA, MATRIZ SWOT E CUIDADO DE SI DOS BIBLIOTECÁRIOS}

Segundo o Código de Ética da Federação Internacional de Associações e Instituições de Bibliotecas (IFLA, 2012), logo no início do texto, no preâmbulo, afirma que uma das funções dos códigos de ética é propor para os bibliotecários e demais profissionais da informação uma melhoria contínua de autoconsciência profissional. 
Partindo do princípio que uma autoconscientização tem como objetivo uma melhoria interna de sentimentos e ações, podemos dizer que os bibliotecários podem, através desta dica da IFLA, planejar uma matriz SOWT e identificar forças, fraquezas, ameaças e oportunidades em sua vida profissional.

A autoconsciência, seja em nível pessoal ou profissional, pode também proporcionar ao indivíduo uma maior compreensão de si, um maior cuidado de si através da revisão do estilo de vida. Aqui, temos o cuidado de si tão abordado por Foucault.

[...] para Foucault, o cuidado ético de si é também sempre cuidado político do outro, de modo que a ética é para ambos intrinsecamente política, motivo pelo qual tem de ser pensada como forma de resistência aos poderes de normalização de subjetividade, os quais aprisionam o sujeito nos rótulos préfabricados das identidades sociais (si mesmo impessoal). (DUARTE, 2014, p. 428).

Cuidar de si significa muito mais do que aparenta. A partir do momento que uma pessoa cuida de si, ela está, também, cuidando do outro. O cuidar de si é o primeiro passo para a manutenção de uma consciência limpa. Um bibliotecário ao cuidar de si estará também cuidando do usuário.

\section{MORAL: BREVES DEFINIÇÕES}

Antes de conceituar a Moral, é preciso salientar que, embora semelhantes, Ética e Moral não são a mesma coisa. Nalini (2011) afirma que a Ética é a ciência dos costumes e que a Moral é um dos objetos da Ética, pois é um dos aspectos do comportamento humano.

Podemos dizer que a Ética é a teoria e a Moral é a prática, é o agir partindo de questões e exemplos espelhados da Ética em um determinado contexto onde existam relações humanas que formam os hábitos e ditam as regras neste local. Junqueira (2006) define a Moral como:

[...] um sistema de leis e de valores estudados pela ética que pertence a uma determinada cultura e a um determinado tempo histórico, que tem como característica principal organizar as relações entre os indivíduos de uma determinada comunidade, definindo e prescrevendo comportamentos. (JUNQUEIRA, 2006, p. 28-29).

A Moral está em todos os lugares através de hábitos, costumes, regras, leis, códigos, entre outros. Na sociedade, o ser humano é um ator social que vive procurando sua Moral perfeita, porém ela é intangível, é complexa. Cada ator dessa sociedade delimita seus objetos, suas metas e até mesmo os que não planejam absolutamente nada são contemplados de uma Moral que nem percebem.

O fenômeno moral básico é a força obrigatória das normas que os sujeitos agentes podem infringir. Por isso, todos os conceitos básicos constitutivos para o agir regulado por normas já contêm uma dimensão moral, a qual é tão somente atualizada e esgotada por ocasião de infrações da norma e conflitos. (HABERMAS, 1989, p. 198).

A Moral também deve fazer parte da carreira dos bibliotecários, ao menos é a instrução do Código de Ética e Deontologia dos bibliotecário brasileiros. Conforme o Conselho Federal de Biblioteconomia (CFB, 2018), através da Resolução n. 207/2018, capítulo 3, artigo 6, inciso 2, afirma que um dos deveres do bibliotecário é procurar dignificar moral, ética e profissionalmente a sua categoria através de suas ações. 


\section{CONSCIÊNCIA MORAL E SEUS GRAUS EXISTENCIAIS NAS ATIVIDADES BIBLIOTECÁRIAS}

De uma maneira resumida, podemos dizer que a Consciência Moral é a habilidade intelectual de um indivíduo para saber diferenciar o que julga ser bom ou mal para nortear a sua vida. Abordaremos a Consciência Moral aqui sob o viés da Deontologia e que, segundo Carlin (2007) significa a ciência e/ou estudo dos deveres de cada profissão.

Prezado leitor, recomendo que a partir das próximas linhas você utilize sua imaginação sem ter peso na consciência, pois os exemplos das atividades dos bibliotecários abaixo são os da consciência do autor que vos escreve e existem outras inúmeras situações em que cada grau de Consciência Moral se faz presente nas atividades profissionais dos bibliotecários.

A Consciência Moral é importante para que cada indivíduo construa suas virtudes morais e possa seguir um caminho baseado em ações que rumem para o bem. A seguir, abordaremos os sete graus da Consciência Moral descritas por Langaro (1996) e apontaremos alguns exemplos, sempre relacionando-os aos deveres profissionais do bibliotecário.

\subsection{CONSCIÊNCIA IGNORANTE}

Existem indivíduos que são portadores de consciência ignorante e não a mantém em sua vida profissional por vontade própria, mas simplesmente por estarem em um contexto em que não tiveram a oportunidade de evoluir intelectualmente. Também existem os indivíduos que praticam ações pensando de modo ilícito, não respeitando normas de convívio social e desrespeitando o próximo e a sociedade de modo geral. Nos dois casos, a consciência ignorante está presente.

A consciência ignorante é aquela em que o agente não sabe distinguir adequadamente entre o lícito e o ilícito, entre o ato bom e o ato mau.

É o caso dos irresponsáveis, dos loucos, que agem confusamente, irresponsavelmente. (LANGARO, 1996, p. 29).

Podemos exemplificar a consciência ignorante pensando em um bibliotecário capaz de furtar obras raras de um acervo para sua coleção pessoal. Ele está agindo de maneira ilícita e não sabe usufruir de suas virtudes morais boas para escapar do caminho errado e pode agir por impulso ou premeditadamente por seus objetivos.

Outro exemplo é de um bibliotecário que não cumpre corretamente seu horário de trabalho, ele chega atrasado quase sempre, na hora da entrada, na volta do intervalo, realiza saídas no meio do expediente sem dar satisfação a seus superiores e não se importa em estar errado ou prejudicando a equipe e a unidade de informação no qual trabalha.

A consciência ignorante bloqueia o indivíduo e o deixa em um estado de vazio moral, onde suas ações são tomadas sem pensar, sem refletir antes de agir e o caminho tende a ser o pior, pois quem age sem responsabilidade normalmente acaba por se dar mal.

\subsection{CONSCIÊNCIA CERTA OU RETA}

Não existe bibliotecas, bibliotecários ou serviços de informação com total eficácia. O bibliotecário que afirmar que é perfeito e que tem a consciência perfeita, está enganando a outros e também a si mesmo. O que existe é uma melhoria contínua de busca pela perfeição, mas sempre cabível de erros.

A consciência certa ou reta é o auge bom dos graus do estado existencial da consciência. O bibliotecário que se enquadra aqui é aquele que realiza suas tarefas de maneira prudente, sempre pensando no próximo, sem esquecer-se de si. Ele procura aperfeiçoar cada vez mais suas atividades e tem a capacidade de refletir sobre seus atos e admitir quando está errado. 
A consciência certa ou reta é o estado da consciência que acerta na aplicação dos princípios aos casos concretos; é aquela que distingue, claramente, entre o lícito e o ilícito, entre o que fazer e o que não fazer. É o estado em que a consciência adere e se adapta adequadamente ao dever. Deriva ela da prudência, da reflexão, do estudo, da investigação e da inteira compreensão de sua responsabilidade. (LANGARO, 1996, p. 29).

Um exemplo de bibliotecário com a consciência certa ou reta é aquele que cumpre seus deveres com dignidade, trabalha em sintonia com sua equipe, sabe oferecer tratamento adequado ao usuário, sendo justo e humilde. Também, situações do cotidiano do bibliotecário podem se tornar testes de consciência certa ou reta: imagine um bibliotecário que acha uma carteira ou uma bolsa com grande quantidade de dinheiro dentro e ele tem duas alternativas, procurar o dono e devolver ou ficar com o dinheiro e somente a consciência certa ou reta é quem vai dizer a ele qual o caminho mais correto.

Para ter uma Consciência Moral digna é preciso descobrir as próprias virtudes morais e esse é o maior desafio de quem busca viver com a consciência certa, pois às vezes, a vida profissional pode ser capaz de promover situações em que é preciso saber escolher entre o bom e o mal para não se arrepender depois.

\subsection{CONSCIÊNCIA ERRÔNEA}

O grau de consciência errônea direciona o indivíduo a caminhos e princípios falsos em que sua consciência é iludida pensando estar caminhando rumo ao caminho certo. A consciência errônea causa prejuízo interno e também é capaz de prejudicar outras pessoas ligadas ao indivíduo errante.

A consciência errônea é aquela que leva o agente ao erro, pela qual pensa estar cumprindo o dever moral quando ele não existe. É o estado de consciência que erra na aplicação dos princípios ou que se apoia em princípios falsos, pensando serem verdadeiros: afirma que isto é bom, quando, na verdade, isto é mau. Pode ser invencivelmente errônea ou vencivelmente errônea: na primeira, não há culpa; na segunda, existe a culpa. (LANGARO, 1996, p. 29).

Um exemplo de consciência errônea é um bibliotecário que ao prestar atendimento a um usuário indica materiais baseados em suas convicções, tais como religião ou política e as informações não ajudam a resolver o problema informacional do usuário. Neste caso, o bibliotecário age de forma parcial e equivocada pensando estar fazendo o certo.

A consciência errônea é uma armadilha moral que vai tentando capturar o indivíduo através de mecanismos falsos ou de má-fé e que moldam as ações do mesmo na tentativa de criar virtudes morais erradas.

\subsection{CONSCIÊNCIA DUVIDOSA}

A consciência duvidosa neutraliza as virtudes morais do indivíduo e prejudica o desenvolvimento das tomadas de decisões da consciência moral. Ela deixa o indivíduo sem rumo, sem saber se caminha em direção ao caminho bom ou ruim. Ela é prejudicial, pois para sobreviver é preciso agir.

A consciência duvidosa, de outra parte, é aquela que deixa o juízo do agente em suspenso, que tem dúvidas no agir, no escolher o caminho do agir ou do decidir, porque age com dúvidas na sua decisão. Também é chamada "perplexa", hesitante, insegura. Neste estado, a consciência não chega a emitir um juízo. Pode ocorrer consciência duvidosa em razão do objeto ou em razão do fato: no primeiro caso, se a dúvida recai sobre a existência, ou não, sobre a 
obrigação, ou não, de uma lei; no segundo caso, se a dúvida incide sobre a existência, ou não, de um fato real, particular ou geral.

O que caracteriza esse estado? Fundamentalmente, é a dúvida. É o estado em que nossa consciência não sabe se é lícita ou ilícita a ação que vamos praticar. (LANGARO, 1996, p. 29-30).

Vamos exemplificar a consciência duvidosa em uma situação que ocorre antes do indivíduo tornar-se, de fato, bibliotecário. Na época da graduação o aluno de Biblioteconomia não sabe se realmente quer seguir a profissão e passa a graduação inteira com dúvidas se deve ou não concluir o curso. Ele suspeita estar no curso errado, no caminho errado, mas não muda a direção e mesmo assim completa os estudos.

Depois de formado, este bibliotecário realiza suas tarefas profissionais sempre com a consciência colocando em dúvida seu futuro, se questionando se realmente é o caminho que quer continuar a seguir e não conseguindo desenvolver virtudes morais através de suas ações profissionais. O sentimento de certeza quanto às tomadas de decisões é fundamental para que um indivíduo tenha uma vida profissional de sucesso.

\subsection{CONSCIÊNCIA PROVÁVEL}

A principal característica da consciência provável é a insegurança. Ela interfere nas tomadas de decisões do indivíduo a ponto de deixá-lo inseguro em seus pensamentos e nas suas ações. É semelhante a consciência duvidosa, porém, ao contrário da duvidosa ela faz com que o indivíduo concretize um juízo mesmo estando inseguro de sua decisão.

A consciência provável é aquela que, embora sabendo que pode estar errada, julga lícita, ainda assim, determinada ação. Ela afirma um juízo sem ter a segurança de uma certeza. Escolhe um caminho e acha que ele é provavelmente o melhor. Baseia-se no provável, no "parece ser", sempre admitindo que, a final, o seu juízo pode estar cometendo um erro. (LANGARO, 1996, p. 30).

Para exemplificar uma ação de consciência provável, imagine um bibliotecário que ao catalogar um livro não encontra informações necessárias para tal ação. Ele encontra um site duvidoso que apresenta as informações que procura, e mesmo desconfiando da veracidade das informações, conclui a atividade.

A consciência provável ilude o indivíduo com o sentimento da certeza e mesmo sabendo que o caminho final pode ser o errado, ele segue buscando novas ilusões para amenizar o erro final de sua tomada de decisão.

\subsection{CONSCIÊNCIA LAXA OU LARGA}

A consciência laxa ou larga faz com que o indivíduo se torne um indigente moral consciencial. Pelo fato do indivíduo acatar tudo e não saber dizer não a nada, ele se torna um "ninguém moral" sem conseguir construir sua identidade moral pelo fato de não ter virtudes morais.

A consciência laxa ou larga é aquele estado de consciência que, com leviandade, sem se preocupar com qualquer análise, julga que qualquer solução é boa, qualquer caminho serve. Aceita tudo como lícito e bom. Este estado de consciência é também chamado "consciência farisaica". Leva o agente a uma total insensibilidade moral. (LANGARO, 1996, p. 30).

Um exemplo de situação em que ocorre a consciência laxa ou larga é o de um bibliotecário que recebe a devolução de um livro de um usuário e mesmo percebendo que o 
livro não está em estado normal de conservação devido a danos provocados pelo próprio usuário, simplesmente recebe a devolução e não diz nada.

Outro exemplo é de um bibliotecário que percebe que alguns usuários estão conversando em tom alto e atrapalhando outras pessoas que querem ler ou estudar e mesmo assim ele deixa a situação ocorrer normalmente. A consciência laxa ou larga tira a capacidade de ação do indivíduo fazendo com que o mesmo não seja capaz de julgar moralmente ao próximo e nem a si mesmo.

\subsection{CONSCIÊNCIA ESCRUPULOSA}

Este grau de consciência moral é capaz de deixar o indivíduo com pensamentos como os de alguém que sofre dos transtornos relacionados à ansiedade, tais como o transtorno do pânico, transtorno obsessivo-compulsivo (TOC), entre outros. O indivíduo imagina e antevê a maldade e a imoralidade em tudo.

A consciência escrupulosa é o estado contrário à consciência laxa: vê o erro ou a maldade onde eles aí não existem. Sem motivos razoáveis, esta consciência julga que tudo é ilegal, ilícito, pecaminoso e imoral.

Dentro deste estado de consciência toda a ação pode ser errônea, cheia de perigos e de dificuldades. (LANGARO, 1996, p. 30).

Para exemplificar a consciência escrupulosa, imaginamos um bibliotecário em seu ambiente de trabalho que tem a certeza que seus colegas lhe perseguem e na verdade todos o tratam de maneira normal. Outro exemplo é de um bibliotecário que julga um usuário por sua aparência e acredita que ele vai roubar algo da biblioteca quando na verdade, ele só acessou o local para conhecer.

O ser humano necessita de alguns sentimentos não muito agradáveis para sobreviver, sentimentos que o protegem, como o medo, a prudência, mas, se exagerados, passam a prejudicar e não a proteger e é exatamente isto que acontece quando um indivíduo tem suas virtudes morais atacadas pela consciência escrupulosa. Os sentimentos se confundem e passam a atormentar a pessoa e a prejudicá-la principalmente em ocasiões de convívio social.

\subsection{TODAS AS CONSCIÊNCIAS MORAIS NO FUTURO DOS BIBLIOTECÁRIOS}

A Consciência Moral do futuro dos bibliotecários não está na lista descrita acima por Langaro, mas todas as reflexões acerca dessas consciências devem fazer parte da rotina profissional dos bibliotecários para que possam traçar caminhos em prol do bem e da sociedade.

Han (2017) afirma que o sujeito moral é o acusando e o juiz ao mesmo tempo, ou seja, cada indivíduo é responsável por construir sua própria Consciência Moral dentro do seu universo cosmoético. O bibliotecário deve ser capaz de formar juízos para criar suas próprias virtudes morais.

A cada dia surgem novos desafios para os bibliotecários da modernidade e um desses desafios gira em torno da Ética da Informação, que aborda até mesmo os aspectos morais relacionados aos processos e mecanismos de criação, disseminação e preservação da informação.

[...] a abrangência da Ética da Informação está ligada aos aspectos morais e legais que a informação agencia. Ou seja, levando em consideração a complexidade do lidar com informação, o campo perpassa e congrega diversas áreas de estudo e de aplicação, atuando, de modo geral, mas não apenas, a partir da aplicação das tecnologias da comunicação e da informação na sociedade, construindo um sistema reflexivo e crítico do que é tratado. (MEDEIROS, 2017, p. 10). 
É preciso que o bibliotecário cuide da própria consciência para construir uma moral digna e ao mesmo tempo fique atento aos usuários e aos seus contextos informacionais, pois até a informação é digna ou não de ser considerada moral ou imoral.

\section{REFLEXÕES FINAIS}

Tarefa complexa é elaborar algo a partir da Consciência Moral, pois por mais que se pense, reflita e escreva, parece que sempre faltará algum detalhe sobre o assunto, mas não nos abalamos por isto, afinal um dos maiores propósitos da Ética é proporcionar para o ser e para a sociedade momentos contínuos de reflexão.

Os graus da Consciência Moral apresentados no decorrer do texto servem para que o indivíduo pense, repense e reflita sobre suas ações, seja na vida profissional ou pessoal e que assim possa continuar no caminho certo ou que mude de direção, caso sinta que o rumo de sua vida não é o mais adequado.

As universidades com graduação em Biblioteconomia e Ciência da Informação devem abordar mais em seus currículos os assuntos éticos, incluindo assuntos relacionados à Moral. Normalmente existe no currículo do curso uma disciplina obrigatória de Ética e dificilmente são ofertadas disciplinas eletivas sobre o tema.

O bibliotecário brasileiro deve centrar seus pensamentos e suas ações para construir uma Consciência Moral digna não somente para si, mas também para os usuários da unidade de informação em que atua. Em um país miserável de moral digna, principalmente nas questões políticas, aquelas cujo exemplo deveria partir, qualquer ação de honestidade é bem-vinda.

\section{REFERÊNCIAS}

ALMEIDA, Julio. Qualificações da consciência. Foz do Iguaçu: Editares, 2005.

CARLIN, Volnei Ivo. Deontologia jurídica: ética e justiça. 4. ed. Florianópolis: Conceito Editorial, 2007.

CONSELHO FEDERAL DE BIBLIOTECONOMIA. Resolução CFB n. 207/2018 de 07 de novembro de 2018. Aprova o Código de Ética e Deontologia do Bibliotecário brasileiro, que fixa as normas orientadoras de conduta no exercício de suas atividades profissionais. Disponível em: http://www.crb8.org.br/resolucao-cfb-no-2072018-codigo-de-etica-e-deontologia-dobibliotecario/. Acesso em: 21 Nov. 2018.

DAMÁSIO, António. O mistério da consciência: do corpo e das emoções ao conhecimento de si. São Paulo: Companhia das Letras, 2000.

DUARTE, André. Vidas em risco: crítica do presente em Heidegger, Arendt e Foucault. Rio de Janeiro: Forense Universitária, 2014.

HABERMAS, Jürgen. Consciência moral e agir comunicativo. Rio de Janeiro: Tempo Brasileiro, 1989.

HAN, Byung-Chul. Sociedade do cansaço. Tradução: Enio Paulo Giachini. 2. ed. Petrópolis, RJ: Vozes, 2017. 
IFLA. Código de ética da IFLA para bibliotecários e outros profissionais da informação (versão integral). Disponível em: https://www.ifla.org/publications/node/11092. Acesso em: 25 Nov. 2018.

JUNQUEIRA, Camila. Ética e consciência moral na psicanálise. São Paulo: Via Lettera, 2006.

LANGARO, Luiz Lima. Curso de deontologia jurídica. 2. ed. São Paulo: Saraiva, 1996.

NALINI, José Renato. Ética geral e profissional. 8. ed., rev., atual. E ampl. São Paulo: Revista dos Tribunais, 2011.

MEDEIROS, Jackson da Silva. A ética da informação em simetria ontológica: notas para uma aproximação metodológica. Comunicação \& Informação, Goiânia, v. 20, n. 1, p. 25, jan./jun. 2017. 